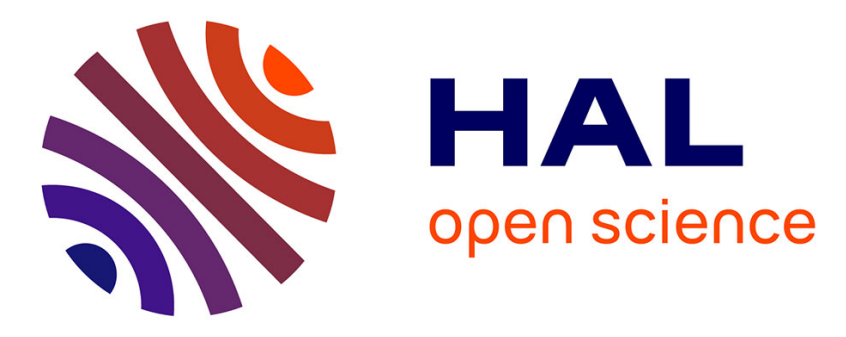

\title{
On the short- and long-run efficiency of energy and precious metal markets
}

Mohamed El Hedi Arouri, Shawkat Hammoudeh, Duc Khuong Nguyen, Amine Lahiani

\section{- To cite this version:}

Mohamed El Hedi Arouri, Shawkat Hammoudeh, Duc Khuong Nguyen, Amine Lahiani. On the shortand long-run efficiency of energy and precious metal markets. 2013. hal-00798036

\section{HAL Id: hal-00798036 https://hal.science/hal-00798036}

Preprint submitted on 7 Mar 2013

HAL is a multi-disciplinary open access archive for the deposit and dissemination of scientific research documents, whether they are published or not. The documents may come from teaching and research institutions in France or abroad, or from public or private research centers.
L'archive ouverte pluridisciplinaire HAL, est destinée au dépôt et à la diffusion de documents scientifiques de niveau recherche, publiés ou non, émanant des établissements d'enseignement et de recherche français ou étrangers, des laboratoires publics ou privés. 


\title{
On the short- and long-run efficiency of energy and precious metal markets
}

\author{
Mohamed El Hedi Arouri ${ }^{\mathrm{a}}$, Shawkat Hammoudeh ${ }^{\mathrm{b}}$, Amine Lahiani ${ }^{\mathrm{c}}$, and Duc Khuong Ngu- \\ yen $^{\mathrm{d}}$ \\ a'University of Auvergne and EDHEC Business School, France. mohamed.arouri@edhec.edu \\ ${ }^{\mathrm{b}}$ LeBow College of Business, Drexel University, USA. Shawkat.M.Hammoudeh@drexel.edu; \\ ${ }^{c}$ LEO, University of Orleans and ESC Rennes Business School, France. amine.lahiani@univ-orleans.fr; \\ ${ }^{\mathrm{d} I S C}$ Paris School of Management, France. dnguyen@iscparis.com
}

\begin{abstract}
This article contributes to the related literature by empirically investigating the efficiency of nine energy and precious metal markets over the last decades, employing several pronounced models. We test for both the shortand the long-run efficiency using, in addition to linear cointegration models, nonlinear cointegration and errorcorrection models (ECM) which allow the efficiency intensity to change per regime. Our findings can be summarized as follows: $i$ ) futures prices are found to be cointegrated with spot prices, but they do not constitute unbiased predictors of future spot prices; $i$ ) the hypothesis of risk neutrality is rejected and there is some evidence of time-varying risk premia; iii) the short-run efficiency hypothesis is rejected, suggesting that using past futures price returns improves the modeling and forecasting of future spot prices; and $i v$ ) the nonlinear modeling suggests the presence of two distinct regimes where in the first regime the efficiency hypothesis is supported, whereas in the second it is rejected. The empirical findings have important implications for producers, hedgers, speculators and policymakers.
\end{abstract}

Keywords: market efficiency, precious metals, energy markets, linear and nonlinear ECM models JEL Classifications: C3, C5, G1 


\section{Introduction}

International financial markets have known a succession of serious crises since 1987 (e.g., the 1997-1998 Asian crisis, the 2001 dot com recession, the 2001 Argentina economic crisis and the 2007-2010 global financial crisis), which are commonly characterized by high volatility and contagion effects (Forbes and Rigobon, 2002; Lee et al., 2007; Markwat et al., 2009). Recent studies also suggest lower diversification benefits from equity investments due to the increased correlations between equity markets around the world, particularly during times of high and extreme volatility (Chan-Lau et al., 2004; Diamandis, 2009). These stylized facts have undeniably encouraged investors to consider alternative investment instruments as a hedge against increasing risk and uncertainty in equity markets. Energy products (mainly oil, oil-related and natural gas contracts) and precious metals (mainly gold, palladium, platinum and silver) have emerged as natural desirable asset classes for international portfolio diversification because of their different volatile returns and low correlations with stocks (Arouri and Nguyen, 2010; Conovor et al., 2010; Daskalaki and Skiadopoulos, 2011; Hammoudeh and Araújo-Santos, 2012). The flight-to-quality phenomenon equally occurs when financial instability increases and deepens in the stock markets or when the price of oil exhibits long swings. Indeed, most investors, for fears of losses, allocate their investments to precious metals which are viewed as safe-haven and refuge assets during widespread market panics. However, the observed increases in price speculations and the high degree of elastic substitution among energy products and between precious metal contracts in both consumption and production call for careful investigation of their price dynamics. All are more likely to be influenced by demand, supply, and expectations about future business cycles.

Energy and precious metals futures contracts allow hedgers to secure the prices of their expected purchase or sale of energy products and precious metals at a specific delivery date in the future. The prices of futures contracts thus convey information about expectations of market participants concerning the spot prices at the maturity date. Such information is crucial for agents not fully hedged as well as for agents planning for future production or use of precious metals and energy products. The importance of futures prices thus arises in particular with their ability to forecast spot prices at specified future dates as they provide economic agents with means of managing the risks related to trading of energy products or precious metals in the spot markets. While all risk management tools share a common interest, i.e., minimizing the risk against an unfavourable evolution of future spot prices, their use is conditional on some market conditions among which informational efficiency is the most im- 
portant. Having its root in the well-known efficient markets theory of financial economics, informational efficiency refers to the degree to which market prices reflect accurately and instantaneously all the relevant information about the true underlying value of financial securities. In this schema of things, the informational efficiency matters in two main ways. First, if a particular market is inefficient, investors may build up various trading strategies that lead to earning excess returns. Second, if all relevant information is incorporated in financial securities' prices as soon as they appear, new investment capital goes to its highest-valued use. These features thus highlight the necessity of research on the efficiency of asset markets.

The efficient market hypothesis (EMH), formally developed by Fama $(1965,1970)$, has been tested for a variety of asset classes including commodities. As far as the energy and precious metal markets are concerned, this hypothesis implies that futures prices constitute the best unbiased forecasts of future spot prices plus or minus a time-varying risk premium, and thus speculators cannot earn abnormal profits. On the other hand, futures prices are unbiased forecasts of future spot prices if one or more speculators are risk-neutral. Therefore, the question of whether or not commodity prices behave according to the market efficiency hypothesis matters because efficiency enables to know if speculative returns could be earned. To date, several empirical studies have addressed this issue for commodity markets (Booth and Kaen, 1979; Solt and Swanson, 1981; Aggarwal and Sundararaghavan, 1987; Tabak and Cajueiro, 2007; Alvarez-Ramirez et al., 2010; Arouri et al., 2010,2011,2012; Ortiz-Cruz et $a l ., 2012$ ), but their focus is mainly on the stochastic properties of successive spot and/or futures price changes of gold, silver and crude oil.

Comparing to previous studies, this article tests the hypotheses of informational efficiency and risk neutrality for energy and precious metals markets over the short- and the long- run, using both linear and nonlinear techniques among which the exponential smooth transition error-correction model (ESTECM) is of particular interest. Theoretically, a market may be informationally efficient and unbiased in the long run, but may pass through periods of inefficiency in the short run, and vice versa. These different patterns of price behavior have obviously important but also very different implications for market operators. Moreover, because of transaction costs, information asymmetry and investors' heterogeneous expectations, markets can be efficient during a certain regime, and as a result the use of nonlinear models is of particular interest for capturing short-run changes in the efficiency intensity over different regimes. Under the efficient and risk neutrality hypotheses, the futures price will be an optimal forecast of the future spot price at the contract termination. 
In its simplest form, the EMH can be reduced to the joint hypothesis that economic agents are, in the aggregate, endowed with rational expectations and are risk neutral so that the futures price is an unbiased estimator of the future spot price (Taylor, 1995). Furthermore, the efficiency hypothesis also states that asset prices fully and instantaneously reflect all available information so that no traders can consistently earn abnormal profits by speculating in the futures prices. Thus in this paper, we contribute to the literature by proposing an integrated approach to empirically test the market efficiency and risk-neutral hypotheses in presence of nonlinearity at both the short- and long-run levels for petroleum (WTI, gasoline, heating oil, and propane), natural gas and precious metals markets (gold, silver, palladium, and platinum). We particularly examine the dynamic relationships between spot and futures prices of these markets, most of which have not been researched well in the market efficiency literature.

The remainder of this article is organized as follows. Section 2 briefly reviews the related literature. The empirical framework is introduced in Section 3. Section 4 describes the data used and reports the obtained results. Section 5 concludes and discusses the main implications of the empirical results.

\section{Literature review}

As noted earlier, past literature has been mostly concerned by testing the efficiency hypothesis of spot and/or futures markets for crude oil, gold, and silver. For oil and oilrelated product markets, this literature begins with Green and Mork (1991) that examines whether the official prices of crude-oil contracts are efficient in the sense of Fama (1970), i.e., whether the price of a futures contract on crude oil is an efficient predictor of the ex-post spot price at the time of merchandise delivery, if all the relevant information was available at the time when the contract was set up. Using the generalized method of moments (GMM) to make inferences about the predictability of monthly prices on Mideast Light and African Light/North Sea crude oils, Green and Mork (1991) reject the weak-form efficiency for the whole sample period 1978-1985. They however show evidence of efficiency improvement over time when subsample periods are used. More recently, Switzer and El-Khoury (2007) test the efficiency of NYMEX (New York Mercantile Exchange) light sweet crude oil futures contract market during the recent period of extreme volatility, and they find that the prices of crude oil futures contract are cointegrated with the spot prices. Maslyuk and Smyth (2008) 
examine the efficiency of crude oil markets by analyzing the weekly spot and futures prices for both West Texas Intermediate (WTI) and Brent crude oil prices over the period from January 1991 through December 2004. They employ Lagrange Multiplier unit root tests allowing for one and two structural breaks, and show that each of the oil price series follows a random walk, i.e., the crude oil markets under consideration are weak-form efficient. Differently, Shambora and Rossiter (2007) find evidence against the validity of the EMH for NYMEX crude oil futures contracts, as their results from an artificial neural network (ANN) model and several technical trading rules show significant predictability in the futures market for oil. There is also evidence to support the hypothesis of evolving efficiency through time (Tabak and Cajueiro, 2007; Elder and Serletis, 2008; Arouri et al., 2010; Alvarez-Ramirez et al., 2008; Alvarez-Ramirez et al., 2010; Ortiz-Cruz et al., 2012). Tabak and Cajueiro (2007) investigate the time-varying degrees of long-range dependence in the Brent and WTI crude-oil returns over the period 1983-2004 by means of estimating the Lo (1991)'s modified Hurst exponent by rescaled range analysis. They find that crude oil markets have become more efficient over time. The results of Alvarez-Ramirez et al. (2008) are consistent with those of Tabak and Cajueiro (2007), as the crude oil markets they consider converge towards weakform efficiency over time. Using different approaches (i.e., semi-parametric wavelet-based estimator, time-varying parameter model with GARCH effects, and detrended fluctuation analysis), Elder and Serletis (2008), Arouri et al. (2010) and Alvarez-Ramirez et al. (2010) document the presence of time-varying short-term predictability in oil price changes. OrtizCruz et al. (2012) analyze the evolution of the informational complexity and efficiency of the WTI crude oil market through multiscale entropy analysis. They show that the crude oil market is informationally efficient over the study period, except for two periods that correspond to the early 1990s and late 2000s US recessions.

As for metal markets, Goss (1981) uses data from the London Mercantile Exchange (LME) over the period 1971-1978 to examine the hypothesis that futures prices are unbiased predictors of the subsequent spot prices for the markets for copper, tin, lead and zinc. While the null hypothesis for lead and tin is rejected, the author reports contrary results for the case of copper and zinc futures contracts. Goss (1985) revisited his 1981 paper by introducing joint tests for the same metals traded in LME and extending the sample period to cover the period 1966-1984. His results demonstrate that the EMH is generally not rejected. These findings are confirmed by those of Canarella and Pollard (1986) who study both overlapping and non-overlapping data for futures contracts of copper, lead, tin and zinc over the period 
1975-1983. Those authors cannot reject the unbiasedness hypothesis. Gross (1988) proposes a semi-strong test of efficiency of the aluminium and copper markets over the period 19831984. He compares the predictive performance of several competing models and shows that the efficiency hypothesis cannot be rejected. By contrast, Sephton and Cochrane $(1990,1991)$ examine the unbiasedness hypothesis in the LME for six metals over the period 1976-1985, and conclude that the LME for metals is not an efficient market. Chowdhury (1991) and Beck (1994) reach the same conclusion for copper using cointegration models. In a related study, Watkins and McAleer (2006) analyze data on three-month futures contracts for aluminum, aluminum alloy, copper, lead, nickel, tin and zinc. In most of the samples considered for the seven metals markets, cointegration tests detect the existence of only one significant long-run relationship among the futures price, spot price, stock level and interest rate. FiguerolaFerretti and Gilbert (2008) employ a bivariate FIGARCH model accommodating for long memory in volatility process to examine the price dynamics of the LME 3-month aluminum and copper futures markets. They find that the conditional volatility of spot and futures aluminum and copper prices exhibits a common degree of fractional symmetric integration.

Among the metal markets, gold market has received the most attention from academic researchers since this yellow metal is widely viewed as a hedge asset during times of financial turbulences and crises. The dynamic properties of gold prices, including gold futures prices, have been extensively investigated (e.g., Ball et al., 1985; Bertus and Stanhouse, 2001; Ciner, 2001; Choi and Hammoudeh, 2010; Hammoudeh et al., 2011). Tschoegl (1980) examines the efficiency of the gold market with respect to the information contained in sequences of successive price changes and finds that although some short-term dependence exists, nobody can use these return relationships to make abnormal profits. In contrast, Neal (1989) and Beckers (1984) find evidence of market efficiency in the gold futures market and in the gold options market, respectively. Consistently, Marshall and Stengos (1994) test the efficiency of spot gold returns at various frequencies in the context of Sims' instantaneous unpredictability property. They find no evidence of out-of-sample forecastability in the return series, implying that the gold market is weak-form efficient. More recently, Wang et al. (2011) use the multifractal detrended fluctuation analysis to investigate the efficiency and multifractality of the gold prices traded in COMEX during the period 1990-2009. Using the rolling window approach, they find that the gold market became more and more efficient over time, especially after 2001. In addition, the gold market is more efficient during the upward periods than during the downward periods. 
Differently, several studies have focused on the question of whether gold prices can be predicted from information related to other financial and commodity prices. For example, Basu and Clouse (1993) suggest that the gold market is inefficient during the period from October 1, 1989 to September 30, 1990 because of significant correlations between the gold spot market price and other market variables (equity, bond, and currency). Narayan et al. (2010) find evidence of cointegration between gold and oil spot and futures markets, i.e., the oil market can be used to predict the gold market prices and vice versa, implying that these two markets are jointly inefficient.

Kumar (2004) focuses on agricultural commodities in India and finds no evidence of a long-run equilibrium relationship between futures and spot markets. The author concludes that the futures markets are not efficient as they fail to discover prices and provide efficient hedge against the risk emerging from price volatility. Moreover, futures markets appear to be unable to effectively incorporate information. Wang and Ke (2005) use similar methods to investigate the efficiency of the Chinese wheat and soybean futures markets. The authors show a long-term equilibrium relationship between futures prices and spot prices for soybean and a weak short-term efficiency for the soybean futures market. The futures market for wheat is however inefficient, which may be caused by over-speculation and government intervention.

Overall, the empirical results of the previous literature are quite mixed when a single commodity market is considered, i.e., the market under consideration can be efficient or inefficient depending on the particular study. They indicate, however, that commodities markets are generally inefficient when information from other markets is used to predict prices in one particular market. In this paper, we contribute to the above literature by proposing an integrated approach to empirically test the market efficiency and risk-neutral hypotheses at both the short- and long-run levels for energy and precious metals markets. We particularly look at the relationships between spot and futures prices of these markets.

\section{Empirical methodology}

In this section, we discuss four nested linear and nonlinear models to examine the efficiency and risk neutrality hypotheses for energy and precious metal markets over both the short and long run. These models include the linear cointegration, the linear error-correction 
model (ECM), the linear ECM with time-varying volatility, and the exponential smooth transition ECM (ESTECM).

According to the primary speculative efficiency hypothesis, the forward prices are the best unbiased forecast of future spot prices plus or minus a time varying-risk premia (Bilson, 1981). In efficient markets without frictions, the arbitrage free or the cost-of-carry model leads to the following relationship between the future price at time $t\left(F_{t}\right)$ and the spot price at time $t\left(S_{t}\right)$ :

$$
F_{t}=S_{t} e^{(r+c-y)(T-t)}
$$

where $r$ is the interest rate, $c$ the storage cost, $y$ the convenience yield and $T$ the expiration date of the futures contract.

In the literature, the non arbitrage relationship (1) is difficult to test empirically because $c$ and $y$ are not directly observed. Thus, researchers suggest testing the Fama (1970, 1991) weak-form efficiency hypothesis according to which the futures price for a risk-neutral speculator is an unbiased predictor of future spot price:

$$
S_{t}=\alpha+\beta F_{t-i}+\varepsilon_{t}
$$

where $F_{t-i}$ refers to the official price of futures contract maturing in period $t$, and $\varepsilon_{t}$ is the rational expectation error and assumed to be serially uncorrelated.

The market efficiency and the risk neutrality require that the restrictions $\beta=1$ and $\alpha=0$, respectively. The rejection of these restrictions means that either the market is inefficient or a significant risk premia may exist $(\alpha \neq 0)$, making market forecasts biased but possibly efficient. If the relationship (2) does not hold, a risk-neutral speculator can have a "free lunch" and earn money on short or long futures positions.

Econometrically, if the series $S_{t}$ and $F_{t-i}$ are not stationary, the estimation of Eq. (2) encounters the problem of spurious regression, unless the two variables are cointegrated. In the case of cointegrated variables, Eq. (2) expresses the equilibrium long-run relationship between $S_{t}$ and $F_{t-i}$, and thus an error correction model (ECM) can be estimated to investigate the short- and long-run dynamics. This approach allows us to investigate the efficiency hypothesis over time. Indeed, the efficiency hypothesis becomes more complicated when the time dimension is introduced. A market may be efficient in the long run but experiences short 
run inefficiencies. While using standard cointegration techniques enables to test for the longrun efficiency and for a constant average risk premia, the ECM with GARCH-in-mean effects allows testing for the short-run efficiency and a time-varying risk premia.

We should, however, note that the cointegration between $S_{t}$ and $F_{t-i}$ is only a necessary but not a sufficient condition for the market efficiency. While under the cointegration hypothesis, $S_{t}$ and $F_{t-i}$ are governed by the same fundamentals, comove and do not tend to drift apart from each other over time, the validity of the efficient market hypothesis requires that security prices fully reflect all available information and that no profit opportunities be left unexploited (Fama, 1970, 1991). It is then clear that cointegration does not rule out shortrun inefficiencies as past spot and futures prices may improve future spot price forecasts even if $S_{t}$ and $F_{t-i}$ are cointegrated.

If $S_{t}$ and $F_{t-i}$ are cointegrated, we can estimate the following linear ECM:

$$
\Delta S_{t}=\lambda-\rho \varepsilon_{t-1}+b \Delta F_{t-n}+\sum_{i=1}^{p} \phi_{i} \Delta F_{t-n-i}+\sum_{j=1}^{q} \varphi_{j} \Delta S_{t-j}+v_{t}
$$

where $\rho>0$ because changes in the spot price respond to deviations from the long-run equilibrium given by Eq. (2) and $v_{t}$ is a stationary error term.

Identifying Eq. (2) and Eq. (3), the efficiency hypothesis implies that $\rho=1, \lambda=\rho \alpha$, $b=\rho \beta \neq 0$ and $\phi_{i}=\varphi_{j}=0$. If these restrictions do not hold, past spot and futures prices can be used to improve the forecasts of future spot price developments, which goes against the market efficiency hypothesis.

According to Eq. (3), the short-run market efficiency can be investigated by testing: $i$ ) $b=\rho \beta \neq 0$ as any information about futures price change is instantaneously reflected in the current spot price change; ii) $\phi_{i}=\varphi_{j}=0$ as past future and spot price changes are already reflected in the current prices and iii) $\rho=1$ to have a stationary relationship. Note that Eq. (3) allows for the existence of a significant risk premium as we do not impose the restriction $\alpha=0$ as required in Eq. 2. Moreover, from Eq. (2) we learn that $\beta$ is the coefficient of $F_{t-i}$ and that for the long-run market efficiency to hold this should be equal to unity ( $\beta=1$ ). 
To sum up, if the tests from Eq. (2) do not lead to rejection of the long-run efficiency hypothesis (i.e., $S_{t}$ and $F_{t-i}$ are cointegrated and $\beta=1$ ), the restrictions imposed to test the short-run market efficiency hypothesis based on Eq. (3) are:

(H1): $\rho=1, \phi_{i}=\varphi_{j}=0, b=1$ and $\lambda=0$ under risk neutrality hypothesis;

(H2): $\rho=1, \phi_{i}=\varphi_{j}=0, b=1$ and $\lambda \neq 0$ under constant risk premia hypothesis;

(H3): $\rho=1, \phi_{i}=\varphi_{j}=0, b=1$ and $\lambda=\lambda(t)$ under time-varying risk premia hypothesis.

Finally, given the extensive volatility observed in the metal and energy markets over the last decades, GARCH(1,1)-in-mean approach can be used to test for a time-varying risk premia. That is, to test for the hypothesis (H3), the risk premia is assumed to be a function of the conditional standard deviation of the change in the spot price. In this context, Eq. (3) can be rewritten as follows:

$$
\begin{aligned}
& \Delta S_{t}=\lambda+\gamma h_{t}-\rho \varepsilon_{t-1}+b \Delta F_{t-n}+\sum_{i=1}^{p} \phi_{i} \Delta F_{t-n-i}+\sum_{j=1}^{q} \varphi_{j} \Delta S_{t-j}+v_{t} \\
& h_{t}^{2}=r+k v_{t-1}^{2}+l h_{t-1}^{2}
\end{aligned}
$$

Several studies have recently shown some evidence of nonlinearity and asymmetry in energy and metal price dynamics (e.g., McMillan and Quiroga, 2008; Ahti, 2009; Arouri and Nguyen, 2010). These characteristics may be explained by different factors such as transactions costs, information asymmetry, and agent heterogeneity. Such market imperfections constitute important barriers to efficiency insofar as they discourage arbitrage operations and prevent asset prices to converge to their efficient level. To the extent that these imperfections may lead to limiting the exchange of assets, particularly when the expected potential gain is inferior to the induced costs, their presence implies two different zones. First, there exists a non-exchange zone within which arbitrage trading is inactive. Prices may continue to fluctuate far from their efficient values with deviations close to a unit root that naturally amplifies the inefficiency of markets. In the second zone, called exchange zone, price adjustment is active and its speed is as high as the disequilibrium between actual prices and their efficient values increases. Therefore, one way to improve the model in Eq. (4) would consist of introducing nonlinearity in the mean equation describing the spot price adjustment and to estimate the following nonlinear smooth transition ECM as given in Eq. (5):

$$
\Delta S_{t}=\lambda-\rho_{1} \varepsilon_{t-1}+b \Delta F_{t-n}+\sum_{i=1}^{p} \phi_{i} \Delta F_{t-n-i}+\sum_{j=1}^{q} \varphi_{j} \Delta S_{t-j}-\rho_{2} \varepsilon_{t-1} \Psi\left(z_{t}, \delta, c\right)+v_{t}
$$


where $\Psi\left(z_{t}, \delta, c\right)=1-\exp \left\{-\delta\left(\varepsilon_{t-1}-c\right)^{2}\right\}$ denotes the transition function that depends on the threshold parameter $(c)$, the transition variable $z_{t}=\varepsilon_{t-1}$ and the transition speed $(\delta)$. The parameters $\rho_{1}$ and $\rho_{2}$ denote the adjustment terms in the first and in the second regimes, respectively. They are the most important parameters, specifying the price adjustment dynamics and defining its convergence speed toward the equilibrium. When $\rho_{2}$ and $\rho_{1}+\rho_{2}$ are significantly positive, even if $\rho_{1}$ is negative, the nonlinear mean reversion in prices is validated. This implies that for a minor disequilibrium, price deviations would diverge from the equilibrium and would be characterized by a unit root or explosive behavior, but for large deviations, the adjustment process would be mean-reverting.

\section{Data and empirical results}

\subsection{Data and preliminary analysis}

The sample data consist of the daily closing spot and futures prices for four precious metal prices (gold, silver, palladium, and platinum), four petroleum products (WTI, gasoline, heating oil, and propane) and natural gas. The futures prices are the closing prices of threemonth futures contracts on the respective commodities. The precious metals are traded in the New York COMEX (Commodity Exchange) and their spot and futures prices are extracted from the Bloomberg database. Petroleum and natural gas prices are obtained from Datastream. All prices are expressed in US dollars, and daily returns are computed by taking the differences in the logarithm of two successive prices. Our study period runs from $01 / 04 / 1999$ to $03 / 31 / 2011$ for precious metals and natural gas, from 01/02/1997 to 01/31/2011 for WTI and heating oil, from 10/03/2005 to 03/31/2011 for gasoline, and from 01/04/1999 to 09/18/2009 for propane. Figure 1 plots spot and futures of the energy and precious metal prices we study.

We first use the Augmented Dickey Fuller (ADF) and Phillips-Perron (PP) unit root tests to check the stability hypothesis for all the price series. We also perform the Andrews and Zivot (1992) test as the ADF and PP test are not robust to eventual structural breaks characterizing the commodity price time-series. The results, reported in Table 1, show that spot and futures prices of almost all commodities are integrated of order one, I(1). The nonstationarity of commodity prices thus gives us the opportunity to investigate their joint dynamics in the long run and to test the efficiency hypothesis over time. 
Figure 1
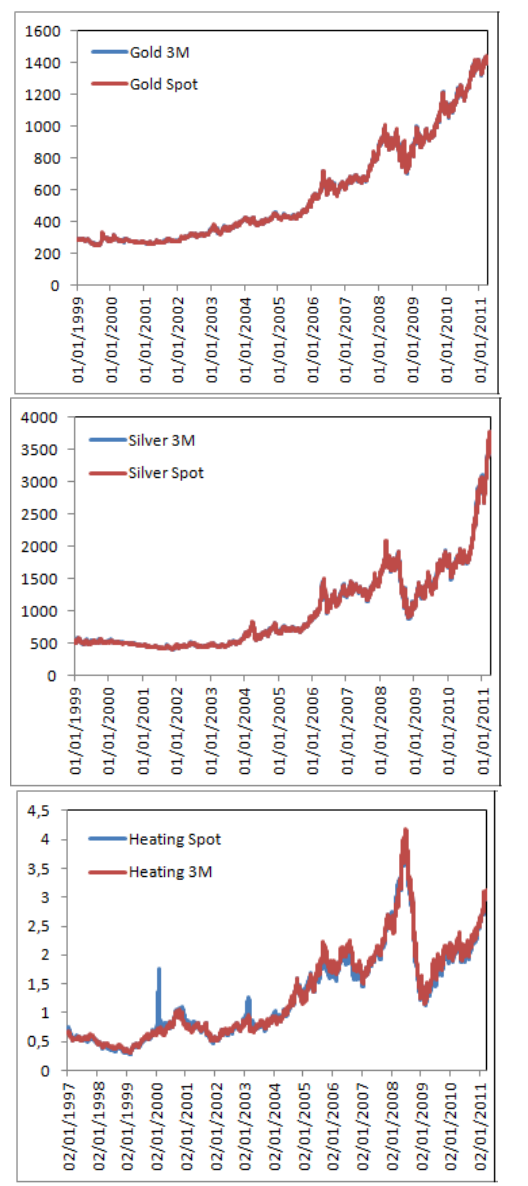

Spot and futures price dynamics
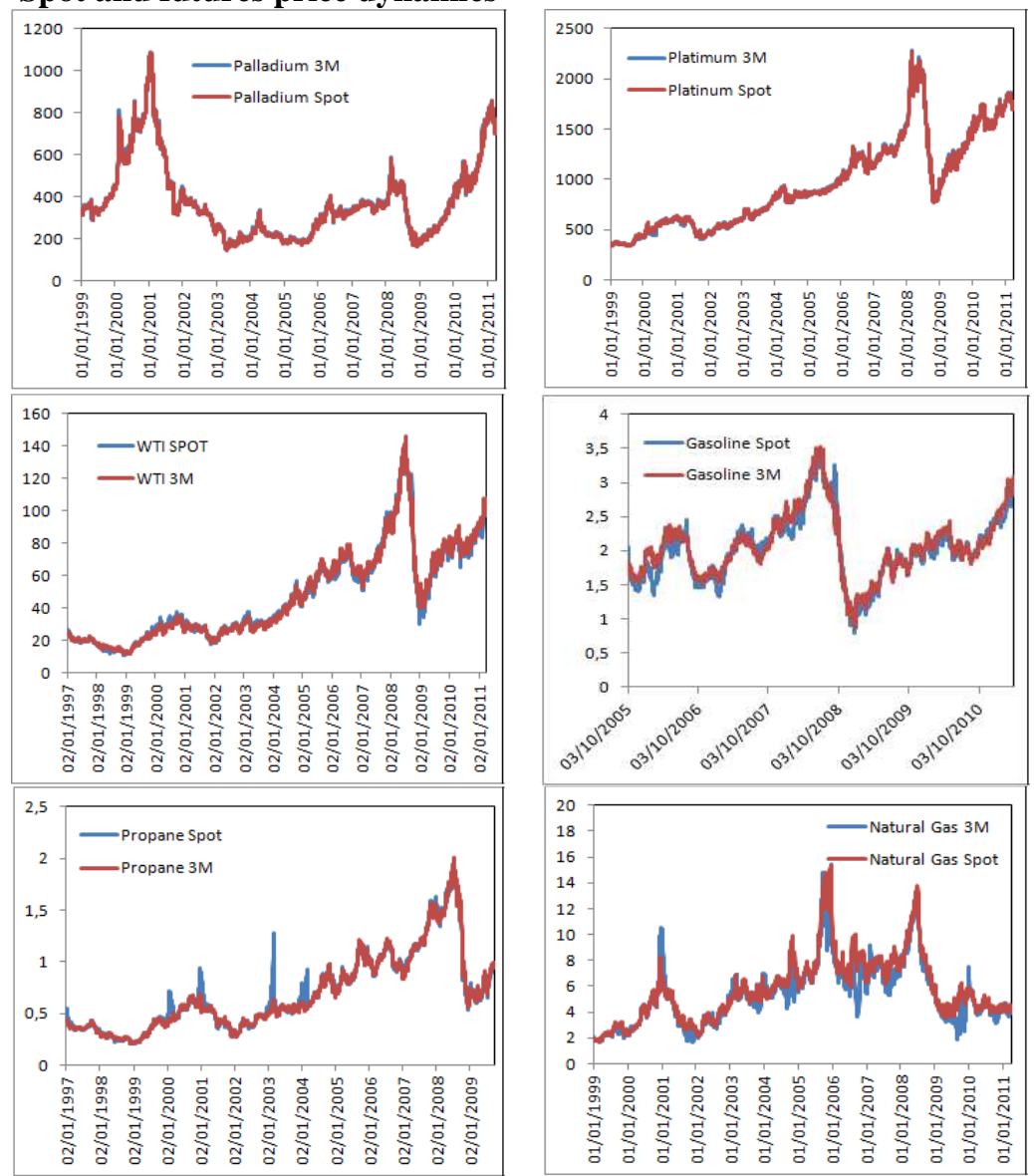

Table 1

Results of unit root tests

\begin{tabular}{|c|c|c|c|c|c|c|}
\hline & \multicolumn{2}{|c|}{$\mathrm{ADF}$} & \multicolumn{2}{|c|}{ PP } & \multicolumn{2}{|c|}{ Z\&A } \\
\hline Series & Level & $\Delta$ & Level & $\Delta$ & Level & $\Delta$ \\
\hline LSWTI & $-3.619(c)$ & $-38.906(a)$ & $-3.437(c)$ & $-81.209(a)$ & -5.096 & -81.147 \\
\hline LSGasoline & $-1.931(\mathrm{~b})$ & $-39.696(a)$ & $-1.887(b)$ & $-39.698(a)$ & -6.160 & -80.110 \\
\hline LSHeating & $-2.763(\mathrm{c})$ & $-42.990(a)$ & $-2.859(\mathrm{c})$ & $-78.379(a)$ & -5.015 & -78.359 \\
\hline LSPropane & $-2.768(\mathrm{c})$ & $-62.128(a)$ & $-2.856(\mathrm{c})$ & $-62.134(a)$ & -3.618 & -62.417 \\
\hline LSGold & $-3.123(c)$ & $-56.689(b)$ & $-3.166(c)$ & $-56.694(b)$ & -4.769 & -56.826 \\
\hline LSSilver & $-1.840(\mathrm{c})$ & $-60.811(c)$ & $-1.815(\mathrm{c})$ & $-60.934(c)$ & -3.351 & -60.999 \\
\hline LSPlatinum & $-2.660(\mathrm{c})$ & $-57.980(b)$ & $-2.534(c)$ & $-58.086(b)$ & -5.153 & -58.152 \\
\hline LSPalladium & $0.582(a)$ & $-54.020(a)$ & $0.527(\mathrm{a})$ & $-54.093(a)$ & -3.229 & -54.278 \\
\hline LSNatural Gas & $-2.451(\mathrm{~b})$ & $-50.765(a)$ & $-2.592(b)$ & $-59.377(a)$ & -5.827 & -59.235 \\
\hline LFWTI & $-3.043(\mathrm{c})$ & $-79.789(a)$ & $-2.934(\mathrm{c})$ & $-79.908(a)$ & -4.478 & -80.110 \\
\hline LFGasoline & $-1.889(b)$ & $-38.849(a)$ & $-1.888(b)$ & $-38.851(a)$ & -5.015 & -80.110 \\
\hline LFHeating & $-2.227(\mathrm{c})$ & $-79.715(a)$ & $-2.200(\mathrm{c})$ & $-79.768(a)$ & -5.015 & -79.841 \\
\hline LFPropane & $-2.328(\mathrm{c})$ & $-58.506(a)$ & $-2.360(\mathrm{c})$ & $-58.571(a)$ & -3.159 & -58.977 \\
\hline LFGold & $-3.150(c)$ & $-55.605(b)$ & $-3.117(\mathrm{c})$ & $-55.626(b)$ & -4.849 & -55.718 \\
\hline LFSilver & $-1.930(\mathrm{c})$ & $-56.964(b)$ & $-1.817(\mathrm{c})$ & $-57.025(b)$ & -3.271 & -57.173 \\
\hline LFPlatinum & $-2.608(\mathrm{c})$ & $-55.689(b)$ & $-2.563(\mathrm{c})$ & $-55.689(b)$ & -5.244 & -55.861 \\
\hline LFPalladium & $0.514(a)$ & $-51.400(a)$ & $0.547(\mathrm{a})$ & $-51.325(c)$ & -3.221 & -51.683 \\
\hline LFNatural Gas & $-2.054(\mathrm{~b})$ & $-63.141(a)$ & $-2.009(b)$ & $-60.129(a)$ & -4.746 & -63.220 \\
\hline
\end{tabular}

Note: LS and LF designate respectively the spot and futures prices in logarithm. The logarithmic transformation aims to reduce the variance of all series. "Level" and " $\Delta$ " designate respectively series in level and those in the first difference. (a): model with neither trend nor constant; (b): model with constant but without trend and (c): model with trend and constant. The critical values for the ADF and PP tests at the 5\% level are -1.95 for model (a), -2.89 for model (b) and -3.45 for model (c). The critical value for the Zivot and Andrews (1992) test, denoted by Z\&A, is -5.08 at the $5 \%$ level. Numbers in bold face indicate that the null hypothesis of unit root is rejected at the $5 \%$ level. 
Table 2 summarizes the summary statistics for the daily spot and futures returns of the commodities, as well as their stochastic properties. On average, we find that over our sample period the precious metals have higher daily returns than energy products. The highest average returns are obtained for the spot silver and silver futures $(0.063 \%)$, followed closely by the average returns on spot gold and gold futures $(0.050 \%)$, and on spot platinum and platinum futures. This confirms the saying on Wall Street "if you want to buy gold, buy silver" (Hammoudeh et al., 2011). The spot returns of natural gas yield a negative return average ($0.001 \%$ ), while its futures contracts on natural gas generate the lowest positive average $(0.012 \%)$. This is most likely has to do the discovery of the new extraction technique hydraulic drilling. ${ }^{1}$

Table 2

Descriptive statistics and stochastic properties of return series

\begin{tabular}{|c|c|c|c|c|c|c|c|c|c|}
\hline & WTI & Gasoline & Heating & Propane & Gold & Silver & Platinum & Palladium & Natural gas \\
\hline \multicolumn{10}{|c|}{ Panel A - Spot Returns } \\
\hline Mean $(\times 100)$ & 0.017 & 0.016 & 0.030 & 0.031 & 0.050 & 0.063 & 0.049 & 0.026 & -0.001 \\
\hline Std. dev. & 0.026 & 0.027 & 0.026 & 0.025 & 0.011 & 0.019 & 0.016 & 0.022 & 0.046 \\
\hline Skewness & -0.769 & -0.164 & -1.606 & -2.454 & -0.070 & -0.422 & -0.466 & -0.312 & 0.488 \\
\hline Kurtosis & 17.315 & 5.882 & 39.747 & 67.328 & 8.315 & 11.045 & 15.958 & 9.146 & 22.689 \\
\hline JB & $55764^{\mathrm{a}}$ & $528^{\mathrm{a}}$ & $359853^{\mathrm{a}}$ & $676889^{\mathrm{a}}$ & $3762^{\mathrm{a}}$ & $8709^{a}$ & $22463^{\mathrm{a}}$ & $5080^{\mathrm{a}}$ & $59575^{\mathrm{a}}$ \\
\hline $\mathrm{Q}(5)$ & $15.725^{\mathrm{a}}$ & 3.582 & 3.158 & 4.070 & 3.021 & 8.592 & 3.808 & $15.076^{b}$ & $14.507^{b}$ \\
\hline$Q^{2}(5)$ & $375.217^{\mathrm{a}}$ & $225.870^{\mathrm{a}}$ & $1340.755^{\mathrm{a}}$ & $142.534^{\mathrm{a}}$ & $338.435^{\mathrm{a}}$ & $123.858^{\mathrm{a}}$ & $218.735^{\mathrm{a}}$ & $243.427^{\mathrm{a}}$ & $1814.547^{\mathrm{a}}$ \\
\hline ARCH (10) & $64.601^{\mathrm{a}}$ & $20.630^{\mathrm{a}}$ & $56.800^{\mathrm{a}}$ & $33.923^{\mathrm{a}}$ & $19.322^{b}$ & $25.887^{\mathrm{a}}$ & 15.119 & $34.726^{\mathrm{a}}$ & $44.121^{\mathrm{a}}$ \\
\hline \multicolumn{10}{|c|}{ Panel B - Futures Returns } \\
\hline $\operatorname{Mean}(\times 100)$ & 0.019 & 0.020 & 0.030 & 0.033 & 0.050 & 0.063 & 0.049 & 0.026 & 0.012 \\
\hline Std. dev. & 0.020 & 0.024 & 0.019 & 0.019 & 0.011 & 0.019 & 0.015 & 0.022 & 0.030 \\
\hline Skewness & $\begin{array}{l}-0.789 \\
\end{array}$ & -0.058 & -0.744 & -1.037 & 0.186 & -0.779 & 0.201 & -0.273 & 0.053 \\
\hline Kurtosis & 15.497 & 6.165 & 13.815 & 15.112 & 9.053 & 10.481 & 18.735 & 7.447 & 9.117 \\
\hline JB & $42683^{\mathrm{a}}$ & $629^{\mathrm{a}}$ & $31522^{\mathrm{a}}$ & $24560^{\mathrm{a}}$ & $4895^{\mathrm{a}}$ & $7771^{\mathrm{a}}$ & $32974^{\mathrm{a}}$ & $2672^{\mathrm{a}}$ & $5739^{a}$ \\
\hline $\mathrm{Q}(5)$ & $10.194^{c}$ & 3.158 & 4.770 & 9.106 & 7.554 & 0.825 & 4.236 & $17.628^{\mathrm{a}}$ & $9.499^{c}$ \\
\hline $\mathrm{Q}^{2}(5)$ & $245.635^{\mathrm{a}}$ & $311.957^{\mathrm{a}}$ & $185.589^{\mathrm{a}}$ & $279.421^{\mathrm{a}}$ & $231.889^{\mathrm{a}}$ & $272.506^{\mathrm{a}}$ & $52.174^{\mathrm{a}}$ & $310.637^{\mathrm{a}}$ & $50.478^{\mathrm{a}}$ \\
\hline ARCH (10) & $42.791^{\mathrm{a}}$ & $16.576^{\mathrm{c}}$ & 14.986 & $29.900^{\mathrm{a}}$ & $28.779^{\mathrm{a}}$ & 13.250 & 13.441 & $42.319^{\mathrm{a}}$ & $46.587^{\mathrm{a}}$ \\
\hline
\end{tabular}

Notes: JB and ARCH(10) are respectively the empirical statistics of Jarque-Bera test for normality and the LM $\mathrm{ARCH}$ test for conditional heteroscedasticity. $\mathrm{Q}(5)$ and $\mathrm{Q}^{2}(5)$ refer to the empirical statistics of Ljung-Box test for serial correlation applied to return and squared return series, respectively. ${ }^{\mathrm{a}}$, ${ }^{\mathrm{b}}$, and ${ }^{\mathrm{c}}$ indicate the rejection of the null hypothesis of normality and no $\mathrm{ARCH}$ effects at the $1 \%, 5 \%$ and $10 \%$, respectively.

The unconditional volatility of all the daily spot and futures returns, as measured by standard deviations, is substantial with daily values ranging from 0.011 (gold spot and gold futures) to 0.046 (natural gas). Energy products are more volatile than precious metals. With respect to the risk-return profile, natural gas spot and futures returns experienced the lowest performance as they have the highest volatility, but the lowest returns. Gold spot and futures returns have the highest risk-adjusted return ratio followed by silver spot and futures returns and platinum spot and futures returns. These findings suggest that most precious metals might

\footnotetext{
${ }^{1}$ http://en.wikipedia.org/wiki/Drilling_rig
} 
be a good hedge for portfolios of stocks and other assets, especially when financial markets pass through periods of turbulences and crises.

The descriptive statistics also show that skewness is negative in most cases and that excess kurtosis is highly significant. Clearly, most of the energy and precious metal returns have fatter tails and longer left tails (i.e., the probability of observing extreme negative returns is higher) than the normal distribution. The Jarque-Bera test (JB) confirms these findings since the normality is strongly rejected for all cases at the $1 \%$ level. The Ljung-Box statistics, $\mathrm{Q}(5)$ and $\mathrm{Q}^{2}(5)$, indicate strong evidence of autocorrelation in squared returns, but only some evidence of autocorrelation in spot and futures returns (WTI, palladium and natural gas). These results typically show signs of high degree of persistence in the conditional volatility process of energy and precious metal price returns. Results from the ARCH tests for conditional heteroscedasticity are consistent with those from the Ljung-Box test applied to squared returns as ARCH effects are significantly present in almost all return series. Taken together, these findings suggest the usefulness and the suitability of GARCH-type models for modeling the time-varying conditional volatility of the considered commodities.

Overall, we observe that spot and futures price returns of our commodities follow similar dynamic patterns in general, which is a priori not contradictory to the speculative efficiency. We next investigate the cointegration and efficiency hypothesis using both price and return series.

\subsection{Cointegration tests and long-run analysis}

\subsubsection{Cointegration results}

We first estimate Eq. (2) in order to investigate the long-run relationship between spot and futures prices of each commodity asset. We then test the null hypothesis of cointegration using the Engle-Granger framework and the Johansen procedure. The optimal number of lags is 13 as it is selected by both AIC and BIC information criteria. ${ }^{2}$ Results of cointegration tests are reported in Tables 3-4.

From Table 3, we see that both ADF and Z\&A tests do not reject the cointegration hypothesis, which suggests that spot and futures prices of all commodities we consider converge towards a long-run equilibrium. When the Johansen procedure is used to test for cointegration (Table 4), we reach the same conclusion for all commodities, except for gasoline

\footnotetext{
${ }^{2}$ The results for the selection of optimal lag length in linear cointegration framework can be made entirely available on request addressed to the corresponding author.
} 
and natural gas where we find two cointegration relationships. For these latter commodities, spot and futures prices are not cointegrated and that a VAR model is sufficient to model their dynamic interactions. Overall, the results from both tests suggest that the same underlying factors derive the spot and futures prices of all considered commodities. ${ }^{3}$

Table 3

Cointegration tests within the Engle-Granger framework

\begin{tabular}{lccccccccc}
\hline & WTI & Gasoline & Heating & Propane & Gold & Silver & Platinum & Palladium & Natural gas \\
\hline \multicolumn{2}{l}{ Model's estimates } & & & & & & & & \\
\hline$\alpha$ & $0.061^{* * *}$ & $-0.061^{* * *}$ & $-0.005^{* * *}$ & $0.0128^{* * *}$ & $-0.006^{* * *}$ & $-0.007^{* * *}$ & $0.097^{* * *}$ & $-0.047^{* * * *}$ & $-0.021^{* * *}$ \\
& $(0.003)$ & $(0.005)$ & $(0.001)$ & $(0.002)$ & $(0.002)$ & $(0.002)$ & $(0.006)$ & $(0.005)$ & $(0.001)$ \\
$\beta$ & $0.983^{* * *}$ & $1.051^{* * * *}$ & $0.986^{* * *}$ & $0.996^{* * *}$ & $1.001^{* * *}$ & $1.001^{* * *}$ & $0.986^{* * *}$ & $1.007^{* * *}$ & $0.974^{* * * *}$ \\
& $(0.001)$ & $(0.006)$ & $(0.002)$ & $(0.002)$ & $(0.000)$ & $(0.000)$ & $(0.001)$ & $(0.001)$ & $(0.004)$ \\
$\bar{R}^{2}$ & 0.994 & 0.947 & 0.985 & 0.981 & 0.999 & 0.999 & 0.986 & 0.998 & 0.994 \\
AIC & -3.238 & -2.771 & -2.342 & -2.404 & -6.330 & -6.000 & -4.671 & -5.021 & -1.331 \\
SIC & -3.236 & -2.764 & -2.340 & -2.401 & -6.327 & -5.996 & -4.668 & -5.017 & -1.328 \\
\hline Residual diagnosis & & & & & & & & \\
\hline Q(10) & 27985.5 & 7318.38 & 41928.9 & 26648.4 & 31.724 & 113.091 & 8870.05 & 217.696 & 24122.1 \\
& {$[0.000]$} & {$[0.000]$} & {$[0.000]$} & {$[0.000]$} & {$[0.000]$} & {$[0.000]$} & {$[0.000]$} & {$[0.000]$} & {$[0.000]$} \\
Q2(10) & 12313 & 3988 & 19993 & 14094 & 517 & 396 & 11665 & 561 & 11795 \\
& {$[0.000]$} & {$[0.000]$} & {$[0.000]$} & {$[0.000]$} & {$[0.000]$} & {$[0.000]$} & {$[0.000]$} & {$[0.000]$} & {$[0.000]$} \\
ARCH(5) & 1447.4 & 459.75 & 3547.0 & 2008.4 & 50.707 & 34.275 & 1667.3 & 68.469 & 2042.8 \\
& {$[0.000]$} & {$[0.000]$} & {$[0.000]$} & {$[0.000]$} & {$[0.000]$} & {$[0.000]$} & {$[0.000]$} & {$[0.000]$} & {$[0.000]$} \\
ARCH(10) & 772.21 & 230.64 & 1827.4 & 1021.8 & 27.269 & 21.928 & 880.17 & 35.168 & 1012.5 \\
& {$[0.000]$} & {$[0.000]$} & {$[0.000]$} & {$[0.000]$} & {$[0.000]$} & {$[0.000]$} & {$[0.000]$} & {$[0.000]$} & {$[0.000]$} \\
ADF & $-6.533^{\mathrm{a}}$ & $-5.671^{\mathrm{a}}$ & $-8.277^{\mathrm{a}}$ & $-6.353^{\mathrm{a}}$ & $-56.458^{\mathrm{a}}$ & $-21.152^{\mathrm{a}}$ & $-10.137^{\mathrm{a}}$ & $-20.698^{\mathrm{a}}$ & $-7.957^{\mathrm{a}}$ \\
$(p)$ & $(13)$ & $(3)$ & $(6)$ & $(6)$ & $(0)$ & $(4)$ & $(4)$ & $(4)$ & $(3)$ \\
Z\&A & -6.883 & -7.121 & -8.775 & -6.666 & -53.936 & -22.217 & -15.831 & -22.010 & -8.305 \\
\hline
\end{tabular}

Notes: $Q(10)$ and $Q^{2}(10)$ refer to the empirical statistics of Ljung-Box test for serial correlation applied to residuals and squared residuals, respectively. ARCH, ADF and Z\&A denote the empirical statistics of the LM ARCH test for conditional heteroscedasticity, and Augmented Dickey-Fuller and Zivot and Andrews (1992) tests for unit root, respectively. The numbers in parenthesis are the standard deviations of the estimated coefficients. $p$ denotes the lag length in the ADF test selected by the SIC information criterion. ${ }^{a}$ denotes the ADF test with neither trend nor constant. ${ }^{* * *}$ indicates significance of the coefficients at the $1 \%$ level. The critical value for the $\mathrm{ADF}$ at the 5\% level is -1.95 . The critical value for the Zivot and Andrews (1992) test at the 5\% level, noted $\mathrm{Z \& A}$, is -5.08 .

Table 4

Results of Johansen cointegration test

\begin{tabular}{lccc}
\hline WTISPOT/WTI3M & Trace Statistic & $5 \%$ Critical Value & $1 \%$ critical value \\
\hline $\mathrm{r}=0^{* * * *}$ & 147.7076 & 15.41 & 20.04 \\
$\mathrm{r}=1$ & 0.7512 & 3.76 & 6.65 \\
\hline GasolineSpot/Gasoline3M & & & \\
\hline $\mathrm{r}=0^{* * * *}$ & 37.5415 & 15.41 & 20.04 \\
$\mathrm{r}=1^{* * * *}$ & 4.6201 & 3.76 & 6.65 \\
\hline HeatingSpot/Heating3M & & & \\
\hline $\mathrm{r}=0^{* * * *}$ & 81.7803 & 15.41 & 20.04 \\
$\mathrm{r}=1$ & 0.6320 & 3.76 & 6.65 \\
\hline PropaneSpot/Propane3M & & & 20.04 \\
\hline $\mathrm{r}=0^{* * * *}$ & 55.9924 & 6.65 \\
$\mathrm{r}=1$ & 1.7286 & 3.76 & 20.04 \\
\hline GoldSpot/Gold3M & & & 6.65 \\
\hline $\mathrm{r}=0^{* * * *}$ & 15.41 & \\
$\mathrm{r}=1$ & 1136.1140 & \\
\hline SilverSpot/Silver3M & 0.3449 & 3.76 & 6.65 \\
\hline $\mathrm{r}=0^{* * * *}$ & & & \\
$\mathrm{r}=1$ & 1236.4860 & & \\
\hline PlatinumSpot/Platinum3M & 0.4974 & 3.76 & \\
\hline
\end{tabular}

\footnotetext{
${ }^{3}$ Similar results are obtained after correction for overlapping observation problems.
} 


\begin{tabular}{lccc}
\hline $\mathrm{r}=0^{* * * *}$ & 185.3933 & 15.41 & 20.04 \\
$\mathrm{r}=1$ & 1.2373 & 3.76 & 6.65 \\
\hline PalladiumSpot/Palladium3M & & & \\
\hline $\mathrm{r}=0^{* * * *}$ & 887.9372 & 15.41 & 20.04 \\
$\mathrm{r}=1$ & 1.0307 & 3.76 & 6.65 \\
\hline NatGasSpot/NatGas3M & & & \\
\hline $\mathrm{r}=0^{* * * *}$ & 98.0159 & 15.41 & 20.04 \\
$\mathrm{r}=1^{* * * *}$ & 3.9412 & 3.76 & 6.65 \\
\hline
\end{tabular}

Notes: Results show one cointegration relationship for the pair of spot and futures prices for all series are cointegrated except for gasoline and natural gas where two cointegration relationships are found, indicating that these series are not cointegrated. ${ }^{* * *}$ indicates the rejection of the null hypothesis at the $1 \%$ level.

\subsubsection{Tests for the speculative efficiency hypothesis}

We now use the Wald test to examine the speculative efficiency hypothesis for the 18 energy and precious metal prices. The results are summarized in Table 5. Accordingly, the risk neutrality hypothesis $(\beta=1)$ and the market efficiency hypothesis $(\alpha=0)$ are individually rejected at the $1 \%$ level for all commodities. This finding thus goes against the first necessary condition for long-run market efficiency. The Wald test also rejects the joint restrictions of market efficiency and risk neutrality ( $\alpha=0$ and $\beta=1)$, indicating that neither the market is efficient and/or that a significant risk premia may exist. These conditions make market forecasts biased but possibly efficient.

Table 5

Results of hypothesis tests

\begin{tabular}{lccccccccc}
\hline & WTI & Gasoline & Heating & Propane & Gold & Silver & Platinum & Palladium & Natural gas \\
\hline$\alpha=0$ & 340.436 & 151.492 & 26.787 & 51.021 & 8.405 & 8.053 & 283.793 & 103.850 & 10.154 \\
& {$[0.000]$} & {$[0.000]$} & {$[0.000]$} & {$[0.000]$} & {$[0.004]$} & {$[0.005]$} & {$[0.000]$} & {$[0.000]$} & {$[0.001]$} \\
$\beta=1$ & 300.591 & 64.165 & 84.081 & 3.368 & 6.645 & 6.367 & 272.188 & 73.754 & 39.058 \\
& {$[0.000]$} & {$[0.000]$} & {$[0.000]$} & {$[0.067]$} & {$[0.010]$} & {$[0.011]$} & {$[0.000]$} & {$[0.000]$} & {$[0.000]$} \\
$\alpha=0, \beta=1$ & 180.287 & 144.888 & 45.358 & 87.923 & 10.915 & 10.643 & 150.944 & 274.956 & 473.820 \\
& {$[0.000]$} & {$[0.000]$} & {$[0.000]$} & {$[0.000]$} & {$[0.000]$} & {$[0.000]$} & {$[0.000]$} & {$[0.000]$} & {$[0.000]$} \\
\hline
\end{tabular}

Notes: the table reports the statistics of Wald test that examines the individual hypotheses of market efficiency and risk neutrality as well as the joint hypothesis ( $\alpha=0$ and $\beta=1)$ as given in Eq. (2). Numbers in brackets are the associated $p$-values.

All in all, our findings show that all the energy and precious metal spot and futures prices are cointegrated, but we are not able to validate the long-run efficiency and the risk-neutrality hypotheses. To the extent that Eq. (2) characterizes the long-run equilibrium between spot and futures prices, we can test the short-run efficiency hypothesis by estimating an ECM. This modeling approach enables us not only to investigate the efficiency hypothesis over time but also to link the short- and long-run efficiency hypotheses through an error-correction adjustment process that predicts future spot prices from information contained in futures contracts. 


\subsection{Short-run analysis}

\subsubsection{Linear ECM estimation}

The estimation results of the linear ECM in Eq. (3) are presented in Table 6. The adjustment terms $\rho$ are significant and have the expected positive sign, thus confirming the findings of our cointegration tests and showing an active mean-reversion mechanism in the relationship between spot and futures prices for all considered commodities. The significance of the coefficients $\phi_{1}$ and $\varphi_{1}$ in numerous cases suggests that the use of past futures and spot returns improves the forecast of future spot returns. Moreover, the econometric specification of Eq. (3) seems to successfully describe the short-run dynamics of spot returns as the Fstatistics of all estimated ECMs are very large and the estimated residuals do not exhibit serial correlation, except for natural gas. However, there is strong and significant evidence of ARCH effects in the residual series, which needed to be accounted for in order to better reproduce the dynamics of spot returns over time.

Table 6

Estimation results of the linear ECM

\begin{tabular}{lccccccccc}
\hline Coefficients & WTI & Gasoline & Heating & Propane & Gold & Silver & \multicolumn{3}{c}{ Platinum Palladium Natural Gas } \\
\hline$\lambda(\times 100)$ & 0.016 & 0.018 & 0.031 & 0.022 & 0.015 & $8.11 \mathrm{E}-5$ & 0.036 & $6.54 \mathrm{E}-5$ & $-8.55 \mathrm{E}-5$ \\
& $(0.031)$ & $(0.067))$ & $(0.033)$ & $(0.039)$ & $(0.018)$ & $(2.10 \mathrm{E}-4)$ & $(0.026)$ & $(3.39 \mathrm{E}-4)$ & $(6.7 \mathrm{E}-4))$ \\
$\rho$ & $0.048^{* * *}$ & $0.054^{* * *}$ & $0.030^{* * *}$ & $0.033^{* * *}$ & $0.684^{* * *}$ & $0.785^{* * *}$ & $0.096^{* * *}$ & $0.615^{* * *}$ & $0.052^{* * *}$ \\
& $(0.008)$ & $(0.012)$ & $(0.004)$ & $(0.006)$ & $(0.044)$ & $(0.027)$ & $(0.013)$ & $(0.033)$ & $(0.005)$ \\
$b$ & 0.024 & $0.147^{* * *}$ & -0.022 & $0.342^{* * *}$ & $0.835^{* * *}$ & $0.976^{* * *}$ & $0.496^{* * *}$ & $0.882^{* * *}$ & $0.724^{* * *}$ \\
& $(0.029)$ & $(0.051)$ & $(0.003)$ & $(0.026)$ & $(0.030$ & $(0.013)$ & $(0.022)$ & $(0.024)$ & $(2.30 \mathrm{E}-5))$ \\
$\phi_{1}$ & $-0.041^{* * *}$ & -0.018 & -0.016 & $0.046^{* *}$ & -0.013 & -0.004 & $0.051^{* * *}$ & -0.017 & -0.023 \\
& $(0.015)$ & $(0.028)$ & $(0.016)$ & $(0.021)$ & $(0.016)$ & $(0.015)$ & $(0.018)$ & $(0.017)$ & $(0,025)$ \\
$\varphi_{1}$ & 0.018 & $-0.087^{* *}$ & $0.053^{* * *}$ & $-0.133^{* * *}$ & $-0.114^{* * *}$ & $-0.098^{* * *}$ & $-0.267^{* * *}$ & $-0.109^{* * *}$ & $-0.039^{* *}$ \\
& $(0.235)$ & $(0.044)$ & $(0.020)$ & $(0.020)$ & $(0.004)$ & $(0.021)$ & $(0.023)$ & $(0.027)$ & $(0.017)$ \\
\hline $\bar{R}^{2}$ & 0.007 & 0.016 & 0.007 & 0.046 & 0.197 & 0.639 & 0.140 & 0.305 & 0.230 \\
\hline $\mathrm{Q}^{2}(4)$ & 1.685 & 2.050 & 4.122 & 2.039 & 1.043 & 2.886 & 7.388 & 3.823 & 15.407 \\
& {$[0.793]$} & {$[0.726]$} & {$[0.389]$} & {$[0.728]$} & {$[0.903]$} & {$[0.577]$} & {$[0.116]$} & {$[0.430]$} & {$[0.004]$} \\
$\mathrm{Q}^{2}(4)$ & 348.021 & 142.821 & 1157.882 & 230.439 & 254.537 & 234.828 & 419.988 & 400.894 & 1657.570 \\
& {$[0.000]$} & {$[0.000]$} & {$[0.000]$} & {$[0.000]$} & {$[0.000]$} & {$[0.000]$} & {$[0.000]$} & {$[0.000]$} & {$[0.000]$} \\
ARCH(10) & 31.352 & 18.378 & 54.731 & 24.174 & 23.156 & 55.208 & 34.516 & 41.831 & 164.909 \\
& {$[0.000]$} & {$[0.048]$} & {$[0.000]$} & {$[0.000]$} & {$[0.000]$} & {$[0.000]$} & {$[0.000]$} & {$[0.000]$} & {$[0.000]$} \\
\hline
\end{tabular}

Note: $\mathrm{Q}(4)$ and $\mathrm{Q}^{2}(4)$ denote the empirical statistics of the Ljung-Box test for serial correlation applied to residuals and squared residuals. ARCH(10) refers to the empirical statistics of the LM ARCH test for conditional heteroscedasticity of residuals. The standard errors are presented in parentheses and the $p$-values are in brackets. ${ }^{*}{ }^{* *}$ and ${ }^{* * *}$ denote significance at the $10 \%, 5 \%$ and $1 \%$ levels, respectively. This table is based on estimation of Eq. (3).

\subsubsection{Tests of the efficiency and risk-neutrality hypotheses}

We present in Table 7 the results from the tests for the hypotheses (H1) and (H2) within the linear ECM framework, i.e., hypothesis of efficiency and risk neutrality $(\rho=1$, $\phi_{i}=\varphi_{j}=0, b=1$ and $\left.\lambda=0\right)$, and the hypothesis of efficiency and constant risk premia $(\rho=1$, $\phi_{i}=\varphi_{j}=0, b=1$ and $\left.\lambda \neq 0\right)$. Both hypotheses are strongly rejected for all the energy and pre- 
cious metal products under consideration. Thus, our findings go against the energy and precious metal market efficiency hypothesis although a mean-reversion process exists. However, these findings may reflect a misspecification associated with the linear adjustment model. To address that, we constraint in Eq. (3) the risk premia to be null or time-invariant, whereas investors may not only require a risk premium but also expect it to be time-varying, given the high volatility of the energy and precious metal markets.

Table 7

Wald test for ECM parameter restrictions

\begin{tabular}{lccccccccc}
\hline Hypothesis & WTI & Gasoline & Heating & Propane & Gold & Silver & Platinum & Palladium & Natural Gas \\
\hline $\mathrm{H} 1: \rho=1, \phi_{i}=\varphi_{j}=0$, & 3067.325 & 1156.960 & 9291.917 & 5832.981 & 12.522 & 20.362 & 948.395 & 36.813 & 6095.862 \\
$b=1$ and $\lambda=0$. & {$[0.000]$} & {$[0.000]$} & {$[0.000]$} & {$[0.000]$} & {$[0.000]$} & {$[0.000]$} & {$[0.000]$} & {$[0.000]$} & {$[0.000]$} \\
\hline $\mathrm{H} 2: \rho=1, \phi=\phi_{j}=0$, & 3834.154 & 1446.192 & 11614.900 & 7291.224 & 15.652 & 25.453 & 1185.494 & 46.017 & 7619.801 \\
$b=1$ and $\lambda \neq 0$ & {$[0.000]$} & {$[0.000]$} & {$[0.000]$} & {$[0.000]$} & {$[0.000]$} & {$[0.000]$} & {$[0.000]$} & {$[0.000]$} & {$[0.000]$} \\
\hline
\end{tabular}

Notes: This table shows the results of the Wald tests (F-statistic) of the hypotheses H1 and H2 based on the estimation results reported in Table 6 . The $p$-values are presented in brackets.

\subsubsection{ECM-GARCH-M and time-varying risk premium estimation}

We now relax the constraints on the risk premium by allowing it to vary through time. It turns out that we can estimate an ECM-GARCH-M model, described in Eq. (4), to characterize the dynamic of each commodity's spot returns. The GARCH-in-Mean specification technique models the risk premia as a function of the conditional volatility of spot price returns. Here, information criteria lead us to retain a GARCH $(1,1)$ specification. We report the obtained results in Table 8, which enable us to test for the hypothesis H3 of efficiency under time-varying risk premia: $\rho=1, \phi_{i}=\varphi_{j}=0, b=1$ and $\lambda=\lambda(t)$.

Table 8

Estimation results of ECM-GARCH-M model

\begin{tabular}{|c|c|c|c|c|c|c|c|c|c|}
\hline & WTI & Gasoline & Heating & Propane & Gold & Silver & Platinum & Palladium & $\begin{array}{c}\text { Natural } \\
\text { gas }\end{array}$ \\
\hline \multicolumn{10}{|c|}{ ECM equation } \\
\hline$\lambda(\times 100)$ & $\begin{array}{c}-3.73 \mathrm{E}-3 \\
(0.073)\end{array}$ & $\begin{array}{c}0.418 \\
(0.309)\end{array}$ & $\begin{array}{c}0.129 \\
(0.092)\end{array}$ & $\begin{array}{c}6.21 \mathrm{E}-3 \\
(0.084)\end{array}$ & $\begin{array}{c}0.066 \\
(0.052)\end{array}$ & $\begin{array}{l}0.093^{* *} \\
(0.038)\end{array}$ & $\begin{array}{l}-0.047 \\
(0.063)\end{array}$ & $\begin{array}{c}0.130 \\
(0.083)\end{array}$ & $\begin{array}{c}0.005^{* * *} \\
(9.11 \mathrm{E}-4)\end{array}$ \\
\hline$\gamma$ & $\begin{array}{c}0.016 \\
(0.035)\end{array}$ & & & & & & & & $\begin{array}{c}-0.136^{* * * *} \\
(0.035)\end{array}$ \\
\hline$\rho$ & $\begin{array}{c}0.052^{* * * *} \\
(0.006)\end{array}$ & $\begin{array}{c}0.036^{* * * *} \\
(0.011)\end{array}$ & $\begin{array}{c}0.024^{* * * *} \\
(0.004)\end{array}$ & $\begin{array}{c}0.053^{* * *} \\
(0.006)\end{array}$ & $\begin{array}{l}0.645^{* * * *} \\
(0.004)\end{array}$ & $\begin{array}{c}0.594^{* * * *} \\
(0.024)\end{array}$ & $\begin{array}{c}0.137^{\text {**** }} \\
(0.015)\end{array}$ & $\begin{array}{c}0.500^{* * * *} \\
(0.025)\end{array}$ & $\begin{array}{l}0.093^{* * * *} \\
(0.005)\end{array}$ \\
\hline$b$ & $\begin{array}{c}0.098^{* * *} \\
(0.029)\end{array}$ & $\begin{array}{c}0.053 \\
(0,045)\end{array}$ & $\begin{array}{l}-0.010 \\
(0.024)\end{array}$ & $\begin{array}{c}0.346^{* * * *} \\
(0.021)\end{array}$ & $\begin{array}{c}0.804^{* * * *} \\
(0.025)\end{array}$ & $\begin{array}{c}0.927^{* * * *} \\
(0.009)\end{array}$ & $\begin{array}{c}0.542^{* * * *} \\
(0.013)\end{array}$ & $\begin{array}{c}0.836^{* * * *} \\
(0.014)\end{array}$ & $\begin{array}{l}0.745^{* * * *} \\
(0.009)\end{array}$ \\
\hline$\phi_{1}$ & $\begin{array}{l}-0.005 \\
(0.013)\end{array}$ & & & & & & & & $\begin{array}{c}0.019 \\
(0.020)\end{array}$ \\
\hline$\varphi_{1}$ & $\begin{array}{l}-0.036 \\
(0.024)\end{array}$ & $\begin{array}{l}-0.014 \\
(0.040)\end{array}$ & $\begin{array}{c}0.033 \\
(0.022)\end{array}$ & $\begin{array}{c}-0.141^{* * * *} \\
(0.022)\end{array}$ & $\begin{array}{c}-0.123^{* * * *} \\
(0.030)\end{array}$ & $\begin{array}{c}-0.157^{* * * *} \\
(-0.019)\end{array}$ & $\begin{array}{c}-0.282^{* * * *} \\
(0.023)\end{array}$ & $\begin{array}{c}-0.157^{* * * *} \\
(0.026)\end{array}$ & $\begin{array}{c}-0.149^{* * * *} \\
(0.019)\end{array}$ \\
\hline \multicolumn{10}{|c|}{ Variance equation } \\
\hline$r(\times 100)$ & $\begin{array}{l}6.77 \mathrm{E}-4^{* * *} \\
(9.90 \mathrm{E}-5)\end{array}$ & $\begin{array}{l}1.28 \mathrm{E}-3^{* * *} \\
(4.11 \mathrm{E}-4)\end{array}$ & $\begin{array}{c}1.23 \mathrm{E}-3^{* * *} \\
(1.44 \mathrm{E}-4)\end{array}$ & $\begin{array}{c}1.10 \mathrm{E}-2^{* * *} \\
(0.001)\end{array}$ & $\begin{array}{l}1.83 \mathrm{E}-4^{* * *} \\
(1.90 \mathrm{E}-5)\end{array}$ & $\begin{array}{l}1.58 \mathrm{E}-4^{* * *} \\
(1.86 \mathrm{E}-5)\end{array}$ & $\begin{array}{l}4.49 \mathrm{E}-4^{* * *} \\
(4.13 \mathrm{E}-5)\end{array}$ & $\begin{array}{l}1.04 \mathrm{E}-3^{* * *} \\
(1.16 \mathrm{E}-4)\end{array}$ & $\begin{array}{c}1.84 \mathrm{E}-3^{* * *} \\
(1.69 \mathrm{E}-4)\end{array}$ \\
\hline$k$ & $\begin{array}{c}0.093^{\text {**** }} \\
(0.004)\end{array}$ & $\begin{array}{c}0.049^{* * *} \\
(0.008)\end{array}$ & $\begin{array}{l}0.103^{* * *} \\
(0.004)\end{array}$ & $\begin{array}{c}0.188^{* * * *} \\
(0.007)\end{array}$ & $\begin{array}{c}0.062^{* * * *} \\
(0.004)\end{array}$ & $\begin{array}{l}0.102^{* * * *} \\
(0.006)\end{array}$ & $\begin{array}{c}0.128^{* * * *} \\
(0.008)\end{array}$ & $\begin{array}{c}0.162^{* * * *} \\
(0.010)\end{array}$ & $\begin{array}{l}0.190^{\text {**** }} \\
(0.009)\end{array}$ \\
\hline$l$ & $\begin{array}{l}0.901^{* * * *} \\
(0.005)\end{array}$ & $\begin{array}{c}0.932^{* * * *} \\
(0.012)\end{array}$ & $\begin{array}{c}0.878^{* * * *} \\
(0.006)\end{array}$ & $\begin{array}{l}0.815^{* * * *} \\
(0.007)\end{array}$ & $\begin{array}{c}0.918^{* * * *} \\
(0.005)\end{array}$ & $\begin{array}{c}0.891^{* * * *} \\
(0.005)\end{array}$ & $\begin{array}{c}0.856^{* * * *} \\
(0.007)\end{array}$ & $\begin{array}{c}0.823^{* * * * *} \\
(0.008)\end{array}$ & $\begin{array}{l}0.826^{* * * *} \\
(0.006)\end{array}$ \\
\hline
\end{tabular}




\begin{tabular}{lccccccccc}
\hline $\bar{R}^{2}$ & 0.005 & 0.015 & 0.006 & 0.041 & 0.196 & 0.632 & 0.136 & 0.302 & 0.205 \\
\hline $\mathrm{Q}(4)$ & 5.355 & 3.266 & 4.439 & 14.850 & 2.220 & 14.354 & 15.514 & 4.008 & 48.298 \\
& {$[0.253]$} & {$[0.514]$} & {$[0.350]$} & {$[0.005]$} & {$[0.695]$} & {$[0.006]$} & {$[0.004]$} & {$[0.405]$} & {$[0.000]$} \\
$\mathrm{Q}^{2}(4)$ & 3.344 & 5.127 & 10.314 & 1.252 & 4.053 & 2.183 & 16.246 & 4.756 & 1.092 \\
& {$[0.502]$} & {$[0.274]$} & {$[0.035]$} & {$[0.869]$} & {$[0.399]$} & {$[0.702]$} & {$[0.003]$} & {$[0.313]$} & {$[0.895]$} \\
\multirow{2}{*}{ ARCH(10) } & 1.396 & 1.436 & 1.373 & 0.249 & 0.637 & 0.603 & 2.442 & 1.118 & 0.468 \\
& {$[0.174]$} & {$[0.158]$} & {$[0.185]$} & {$[0.990]$} & {$[0.782]$} & {$[0.812]$} & {$[0.006]$} & {$[0.343]$} & {$[0.910]$} \\
\hline
\end{tabular}

Notes: $\mathrm{Q}(4)$ and $\mathrm{Q}^{2}(4)$ denote the empirical statistics of the Ljung-Box test for serial correlation applied to residuals and squared residuals. ARCH(10) refers to the empirical statistics of the LM ARCH test for conditional heteroscedasticity of residuals. $K$ represents the ARCH effect, and $l$ the GARCH effect. The standard errors are presented in parentheses and the $p$-values in brackets. ${ }^{* *}$ and ${ }^{* * *}$ represent significance at the $5 \%$ and $1 \%$, respectively. Estimations are based on Eq. (4).

Most estimated coefficients have the expected signs, and the hypotheses of serial correlation and $\mathrm{ARCH}$ effects are rejected in most cases. As for the variance equation, the coefficients of the GARCH specification have the expected signs and are also statistically significant, suggesting the existence of the time-varying pattern of the spot return volatility and confirming the presence of the ARCH effects we found in the return series. However, the coefficient $\gamma$ is significant only for silver and natural gas, and as a result the hypothesis of a timevarying risk premia cannot be validated for the seven other products.

All in all, our findings reveal several interesting facts. First, they underscore a significant cointegration relationship between the spot and futures prices, which favors the first necessary condition for long-run efficiency. Second, the efficiency hypothesis is rather rejected in the short- and long-run. This result implies that the futures prices are not "good" and unbiased estimates of the future spot price and that the past price returns are relevant to forecast future prices. Third, we demonstrate some evidence to support the assumption of timevarying risk premia. These conclusions can have important implications for the energy and precious metal market participants as they suggest that there are still investment opportunities in these markets through speculating on the information incorporated on futures contracts.

\subsubsection{Nonlinear ESTECM and efficiency per regime}

It is also possible to improve the model specification by introducing nonlinearity in the mean-equation describing the spot price adjustment. The specification in Eq. (5) corresponds to a two-regime Exponential Switching Transition ECM (ESTECM) that is often useful to characterize the dynamics of financial time series. In particular, this model allows for a dynamic adjustment between spot and futures price returns to vary according to the prevailing regime. Econometrically, this ESTECM corresponds to the nonlinear form of Eq. (3) which defines the dynamics of spot returns with respect to two different regimes. We estimate an ESTECM for the spot return of each commodity by the nonlinear least squares using 
the estimation procedure detailed in Van Dijk et al. (2002). The main results are summarized in Table 9.

Table 9

Estimation results of ESTECM model

\begin{tabular}{|c|c|c|c|c|c|c|c|c|c|}
\hline Coefficients & WTI & Gasoline & Heating & Propane & Gold & Silver & Platinum & $\begin{array}{l}\text { Palladi- } \\
\text { um }\end{array}$ & $\begin{array}{l}\text { Natural } \\
\text { gas }\end{array}$ \\
\hline \multirow[t]{2}{*}{$\lambda(* 10)$} & 0.003 & -0.003 & $0.016^{* * * *}$ & 0.003 & 0.000 & 0.001 & $0.007^{* * *}$ & 0.002 & -0.003 \\
\hline & $(0.003)$ & $(0.008)$ & $(0.005)$ & (0.004) & $(0.000)$ & $(0.002)$ & $(0.003)$ & $(0.003)$ & $(0.007)$ \\
\hline \multirow[t]{2}{*}{$\rho_{l}$} & $0.453^{\text {**** }}$ & -0.039 & -0.027 & $-0.169^{* * *}$ & $0.401^{* * * *}$ & 0.137 & $0.220^{* * * *}$ & $0.882^{* *^{* *}}$ & $-0.244^{* * *}$ \\
\hline & $(0,052)$ & $(0.106)$ & $(0.018)$ & $(0.084)$ & $(0.082)$ & $(0.184)$ & $(0.044)$ & $(0.087)$ & $(0.084)$ \\
\hline \multirow[t]{2}{*}{$b$} & $0.006^{*}$ & $0.145^{* *}$ & $-0.042^{*}$ & $0.339^{* * *}$ & $0.838^{* * *}$ & $0.976^{* * *}$ & $0.506^{* * *}$ & $0.883^{* * *}$ & $0.725^{* * *}$ \\
\hline & $(0.026)$ & $(0.049)$ & $(0.025)$ & $(0.026)$ & $(0.028)$ & $(0.013)$ & $(0.022)$ & $(0.022)$ & $(0.024)$ \\
\hline \multirow[t]{2}{*}{$\phi_{1}$} & $-0.039^{* * * *}$ & -0.019 & -0.018 & $0.046^{* * *}$ & -0.019 & -0.004 & $0.047^{* *}$ & -0.020 & -0.024 \\
\hline & $(0.015)$ & $(0,028)$ & $(0.015)$ & $(0.020)$ & $(0.017)$ & $(-0.015)$ & $(0.018)$ & $(0.017)$ & $(-0.024)$ \\
\hline \multirow{2}{*}{$\varphi_{1}$} & 0.032 & $-0.085^{*}$ & $0.056^{* * *}$ & $-0.135^{* * *}$ & $-0.107^{* * * *}$ & $-0.098^{* * * *}$ & $-0.254^{* * *}$ & $-0.108^{* * * *}$ & $-0.038^{* * *}$ \\
\hline & $(0.023)$ & $(0.043)$ & $(0.019)$ & $(0.019)$ & $(0.033)$ & $(0.020)$ & $(0.020)$ & $(0.026)$ & $(0.016)$ \\
\hline \multirow[t]{2}{*}{$\rho_{2}$} & $0.416^{* * *}$ & 0.098 & $0.071^{* * * *}$ & $0.204^{* * *}$ & $0.337^{* * *}$ & $0.656^{* * * *}$ & $0.138^{* * *}$ & $0.294^{* * * *}$ & $0.299^{* * * *}$ \\
\hline & $(0,052)$ & $(0.106)$ & $(0.020)$ & $(0.084)$ & $(0.075)$ & $(0.185)$ & $(0.045)$ & $(0.085)$ & $(0.084)$ \\
\hline \multirow[t]{2}{*}{$\delta$} & $13.061^{* * * *}$ & 9.235 & 15.611 & $144.961^{* *}$ & $0.313^{*}$ & $64.721^{* * *}$ & $0.701^{*}$ & $27.704^{* *}$ & $214.039^{* *}$ \\
\hline & (2.617) & $(24.496)$ & (13.840) & (71.269) & $(0.170)$ & (27.148) & $(0.417)$ & (10.864) & (96.982) \\
\hline \multirow[t]{2}{*}{$C$} & $0.156^{* * * *}$ & 0.021 & $-0.049^{* * * *}$ & $-0.091^{* * * *}$ & $0.045^{* * * *}$ & $-0.033^{* * * *}$ & 0.017 & $0.078^{* * * *}$ & $0.188^{* * * *}$ \\
\hline & $(0.002)$ & $(0.019)$ & $(0.015)$ & $(0.002)$ & $(0.003$ & $(4.57 \mathrm{E}-4)$ & $(0.008)$ & $(0.005)$ & $(0.002)$ \\
\hline $\mathrm{Q}(4)$ & 1.367 & 1.921 & 4.083 & 2.029 & 0.527 & 2.755 & 7.132 & 3.675 & 16.076 \\
\hline [p-value] & [0.849] & {$[0.750]$} & [0.395] & {$[0.730]$} & {$[0.970]$} & [0.599] & [0.129] & {$[0.451]$} & {$[0.003]$} \\
\hline $\mathrm{ARCH}(10)$ & 3.271 & 3.034 & 54.400 & 14.359 & 1.139 & 6.800 & 21.101 & 7.507 & 133.046 \\
\hline [p-value] & [0.513] & [0.552] & [0.000] & [0.006] & [0.887] & [0.146] & {$[0.000]$} & [0.111] & {$[0.000]$} \\
\hline $\begin{array}{l}\text { var(nonlinear) } \\
\text { /var(linear) }\end{array}$ & 0.990 & 1.003 & 0.999 & 0.999 & 0.994 & 0.998 & 0.998 & 0.997 & 0.997 \\
\hline
\end{tabular}

Notes: Q(4) denotes the empirical statistics of the Ljung-Box test for serial correlation applied to residuals. $\mathrm{ARCH}(10)$ refers to the empirical statistics of the LM ARCH test for conditional heteroscedasticity of residuals. The standard errors are presented in parentheses while the $p$-values are in brackets. ${ }^{*},{ }^{* *}$ and ${ }^{* * *}$ represent significance at the $10 \%, 5 \%$ and $1 \%$, respectively. This table is based on the estimation of Eq. (5).

The results reported in Table 9 show that for most series there are no remaining serial correlations and ARCH effects in the estimated residual series, which suggest the appropriateness of the ESTECM. Interestingly, in all cases except heating oil, $\rho_{2}>0$ and $\rho_{1}+\rho_{2}>0$. These findings thus show strong evidence of nonlinear mean reversion between spot and futures prices. Moreover, the ratio of residual nonlinear variance to residual linear variance is less than the unity for all series, except gasoline, indicating that the introduction of nonlinearity enables to improve the ability of the traditional ECM to forecast the spot price dynamics. The lagged values of spot and futures returns are also found to significantly affect the spot return dynamics, and consequently we can conclude on the rejection of the weak-form efficiency for the energy and precious metal markets under consideration.

The observed nonlinearity in the behavior of commodity spot returns is clearly displayed via the estimated transition function. Except for heating oil and gasoline, the parameters of the transition function are statistically significant and thus confirm our choice of the exponential function. Two distinct regimes are identified for the dynamic adjustments of spot returns. First, a central regime is established and characterized by small deviations between 
spot and futures prices. Within this regime, futures prices may not contain significant information regarding future spot prices and the price adjustment process may not be active and the arbitrage operations are rather absent. The second regime is activated for large deviations of spot prices from futures prices and when the transition function reaches the unity. In this case, the arbitrage becomes active and futures contracts would provide helpful information to forecast future spot prices. It is obvious that the efficiency hypothesis cannot be rejected if spot return dynamics stay in the first regime. However, when the gap between the spot and futures prices gets wider and wider, the adjustment would become more active, and thus the market for a particular commodity would be considered rather inefficient.

Figure 2

Estimated transition functions

Gold

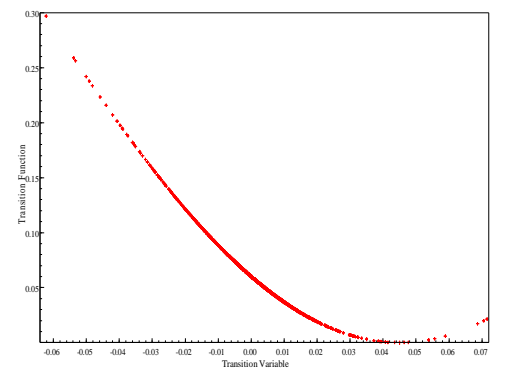

Silver

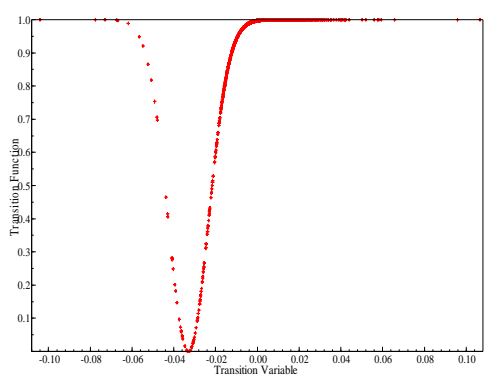

Heating oil

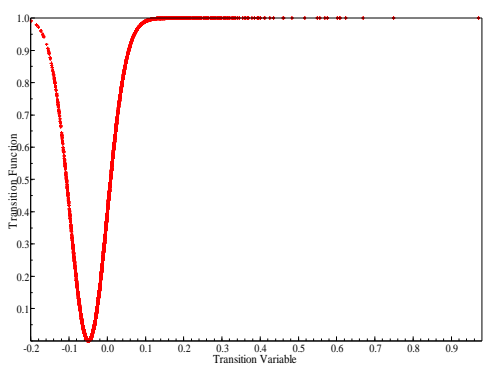

Palladium

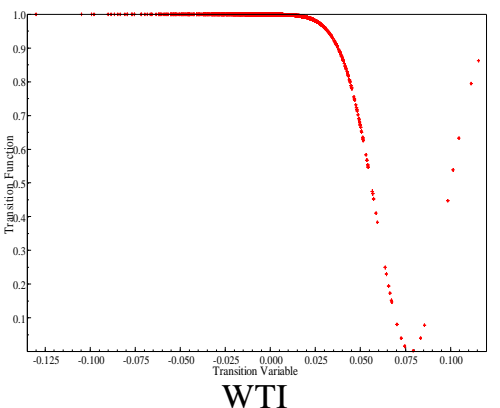

NTI

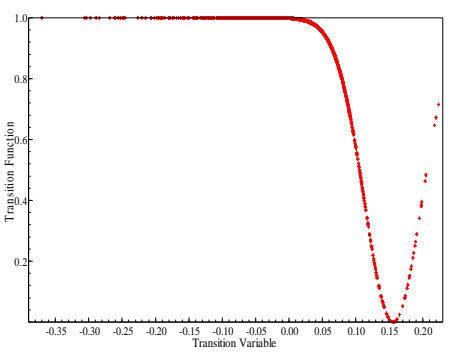

Propane

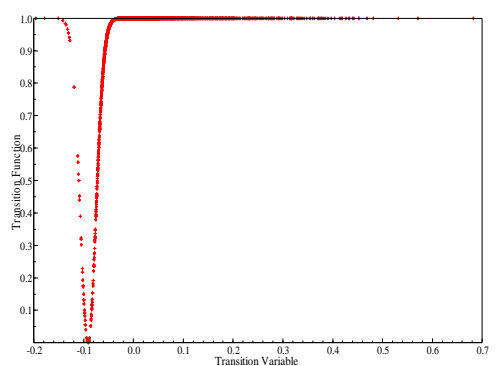

Platinum

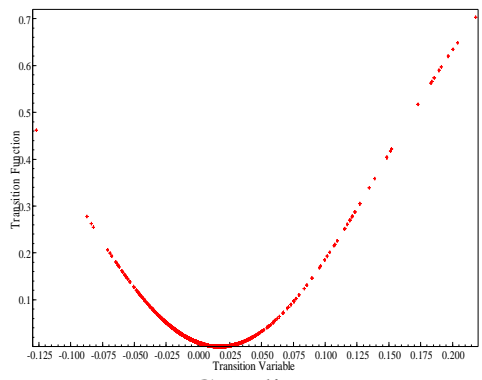

Gasoline

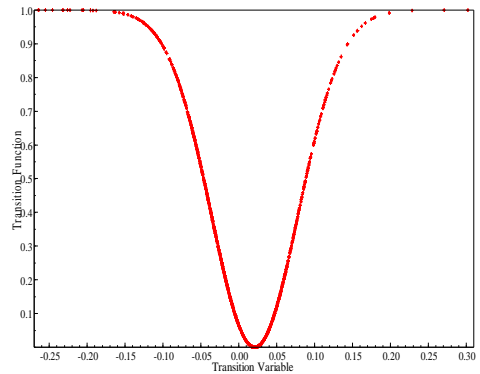

Natural gas

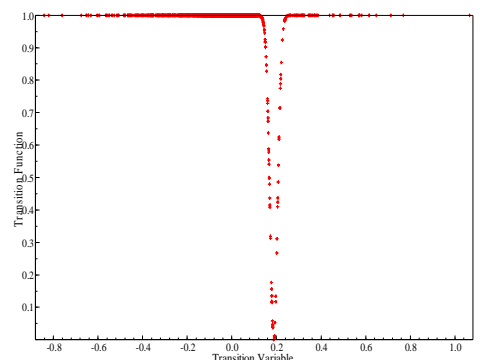

The estimation of the transition speed varies considerably across the energy and precious metal products. The estimated transition functions, plotted in Figure 2 against the transition variable, illustrate the shifts between different regimes and show the relationship between spot and future prices in each regime as well. For all series, the transition function 
reaches unity, which implies that the dynamic adjustment of spot-futures price relationships for each commodity is often activated and that both prices are closely linked. Considering the adjustment speed of commodity prices, we see that with the bigger size of price deviations from the equilibrium, the stronger the mean reversion. Figure 2 also confirms the asymmetry and persistence in the spot-futures price relationship. Therefore, the importance of futures contracts information depends upon the disequilibrium size between spot and futures prices, and the speculative efficient hypothesis for the energy and precious metal markets follows a gradual and time-varying process that is activated by regime.

\section{Conclusion}

In this paper, we provide a comprehensive empirical investigation of the efficiency and risk neutrality hypotheses for nine energy and precious metal markets over the last decades. We apply a wide range of linear and nonlinear econometric techniques to test for both long-run and short-run efficiency. Our main findings can be summarized as follows. First, we show a significant cointegration relationship between commodity spot and futures prices (i.e., they converge towards a common equilibrium in the long run), indicating that both spot and futures prices are governed by common factors and are not good substitutes in diversified portfolios. Second, the efficiency hypothesis is significantly rejected in the short and long run whatever the assumptions on risk premium are. These findings are consistent with the view that the futures prices do not constitute an unbiased predictor of the future spot prices and that past information can relevantly be used to improve the forecasting of future spot prices. Moreover, we find some evidence of time-varying risk premia which underscores the failure of the linear ECM to appropriately specify the relationship between spot and futures markets. Finally, accounting for nonlinearity in the modeling of the spot price adjustment dynamics and defining it through the alternation of different regimes have substantially improved the analysis. More precisely, we point out an on/off nonlinear time-varying relationship between spot and futures prices. The analysis of the adjustment terms of the nonlinear model suggests that the market efficiency hypothesis is rejected when the disequilibrium size between spot and futures prices becomes very high. Market investors and policymakers thus have interest to adapt their actions according to the state of the market (i.e., efficiency vs. inefficiency). If the considered market is in its inefficient state, investors can for example use the information included in the futures contracts to forecast the price development in the spot segment, and market regulators may undertake measures that favor arbitrage activities. 
Summarizing all, our results show that spot market participants can still build profitable strategies based on past information contained in futures prices of those commodities. As far as the considered commodity markets are not efficient, there is a need of searching for optimal allocation and risk hedging of portfolios involving both spot and futures instruments of the same underlying commodity. For instance, most precious metals appear to be a good hedge for portfolios of stocks and other assets, especially when international financial markets pass through periods of turbulences and crises

\section{References}

Aggarwal, R., Sundararaghavan, P.S., 1987. Efficiency of the silver futures market: An empirical study using daily data. Journal of Banking and Finance 11, 49-64.

Ahti, V., 2009. Forecasting commodity prices with nonlinear models. Discussion Paper $n^{\circ} 268$ Helsinki Center of Economic Research.

Alvarez-Ramirez, J., Alvarez, J., Rodriguez, E., 2008. Short-term predictability of crude oil markets: A detrended fluctuation analysis approach. Energy Economics 30, 2645-2656.

Alvarez-Ramirez, J., Alvarez, J., Solis, R., 2010. Crude oil market efficiency and modeling: Insights from the multiscaling autocorrelation pattern. Energy Economics 32, 993-1000.

Andrews, K., Zivot, E., 1992. Further evidence on the great crash, the oil price shock, and the unit root hypothesis. Journal of Business and Economic Statistics 10, 251-270.

Arouri, M.H., Dinh, T.H., Nguyen, D.K., 2010. Time-varying predictability in crude-oil markets: the case of GCC countries. Energy Policy 38, 4371-4380.

Arouri, M.H., Nguyen, D., 2010. Oil prices, stock markets and portfolio investment: Evidence from sector analysis in Europe over the last decade. Energy Policy 38, 4528-4539.

Arouri, M., J. Jouini and D. Nguyen. (2011). "Volatility Spillovers between Oil Prices and Stock Sector Returns: Implications for Portfolio Management." Journal of International Money and Finance, 30(7): 1387-1405.

Arouri, M., Jouini, J. and Nguyen, D.K., 2012. On the impacts of oil price fluctuations on European equity markets: Volatility spillover and hedging effectiveness. Energy Economics.

34, 611-617.

Ball, C.A., Torous, W.A., Tschoegl, A.E., 1985. The degree of price resolution: the case of the gold market. Journal of Futures Markets 5, 29-43.

Basu, S., Clouse, M.L., 1993. A comparative analysis of gold market efficiency using derivative market information. Resources Policy 19, 217-224.

Beck, E.S., 1994. Cointegration and market efficiency in commodities futures markets. Applied Economics 26, 249-57

Beckers, S., 1984. On the efficiency of the gold options market. Journal of Banking and Finance 8, 459-470.

Bertus, M., Stanhouse, B., 2001. Rational speculative bubbles in the gold futures market: An application of dynamic factor analysis. Journal of Futures Market 21, 79-108.

Bilson, J.F.O., 1981. The speculative efficiency hypothesis. Journal of Business 54, 435-451.

Booth, G.G., Kaen, F.R., 1979. Gold and silver spot prices and market information efficiency. Financial Review 14, 21-26.

Canarella, G., Pollard, S.K., 1986. The efficiency of the London metal exchange: A test with overlapping and non-overlapping data. Journal of Banking and Finance 10, 575-93. 
Chan-Lau, JA., Mathieson, D.J., Yao, J.Y., 2004. Extreme contagion in equity markets. IMF Staff Papers 51, 386-408.

Choi, K., Hammoudeh, S., 2010. Volatility behavior of oil, industrial commodity and stock markets in a regimeswitching environment. Energy Policy 38, 4388-4399.

Chowdhury, A.R., 1991. Futures markets efficiency: Evidence from cointegration tests. Journal of Futures Markets 11, 577-589.

Ciner, C., 2001. On the long-run relationship between gold and silver prices: A note. Global Finance Journal 12, 299-303.

Conover, C. M., Jensen, G.R., Johnson, R.R., Mercer, J.M., 2010. Is now the time to add commodities to your portfolio? Journal of Investing 19, 10-19.

Elder, J., Serletis, A., 2008. Long memory in energy futures prices. Review of Financial Economics, 17, 146155.

Diamandis, P.F., 2009. International stock market linkages: Evidence from Latin America. Global Finance Journal 20, 13-30.

Daskalaki, C., and Skiadopoulos, G. (2011). Should investors include commodities in their portfolios after all? New evidence. Journal of Banking and Finance 35, 2606-2626.

Engle, R., Granger, C., 1987. Cointegration and error correction: representation, estimation and testing. Econometrica 55, 251-76.

Fama, E.F., 1965. The behavior of stock market prices. Journal of Business 38, 34-105.

Fama, E.F., 1970. Efficient capital markets: a review of theory and empirical work. Journal of Finance 25, 383417.

Fama, E.F., 1991. Efficient capital markets II. Journal of Finance 46, 1575-1617.

Figuerola-Ferretti, I., Gilbert C., 2008. Commonality in the LME aluminium and copper volatility processes through a FIGARCH lens. Journal of Futures Markets 28, 935-962.

Forbes K. J., Roberto Rigobon, 2002. No contagion, only interdependence: Measuring stock market comovements. Journal of Finance 57, 2223-2261.

Goss, B.A., 1981. The forward pricing function of the London metal exchange. Applied Economics 13, 133150.

Goss, B.A., 1985. The forward pricing function of the London Metal Exchange, Futures Markets: Their Establishment and Performance, London, 157-173.

Green, S.L., Mork, K.A., 1991. Toward efficiency in the crude-oil market. Journal of Applied Econometrics 6, 45-66.

Gross, M., 1988. A semi-strong test of the efficiency of the aluminum and copper markets at the LME. Journal of Futures Markets 8, 67-77.

Hammoudeh, S., Araújo-Santos, P., Al-Hassan, A. 2012. Downside risk management and VaR-based optimal portfolios for precious metals, oil and stocks. North American Journal of Economics and Finance (in press).

Hammoudeh, S., Malik, F., McAleer, M., 2011. Risk management of precious metals. Quarterly Review of Economics and Finance 51, 435-441.

Kumar, S., 2004. Price discovery and market efficiency: evidence from agricultural commodities futures markets. South Asian Journal of Management 11, 32-47.

Lee, H. Y., Wu, H. C., Wang, Y. J., 2007.Contagion effect in financial markets after the South-East Asia Tsunami. Research in International Business and Finance, 21(2), 281-296.

Lo, A., 1991. Long-term memory in stock market prices. Econometrica 59, 1279-1313.

Markwat, T., Kole, E., van Dijk, D., 2009. Contagion as a domino effect in global stock markets. Journal of Banking \& Finance 33 (11), 1996-2012.

Marshall, M., Stengos, T., 1994. Employing conditional variance processes to examine the market efficiency of the gold rates of return. Journal of Economics and Business 46, 355-365. 
Maslyuk, S., Smyth, R., 2008. Unit root properties of crude oil spot and futures prices, Energy Policy 36, 25912600.

McMillan, D.G., Quiroga, G.R., 2008. Efficiency of the INEX spot-futures basis: the impact of the mini-futures. Journal of Futures Markets 28, 398-415.

Narayan, P.K., Narayan, S., Zheng, X., 2010. Gold and oil futures markets: Are markets efficient? Applied Energy 87, 3299-3303.

Neal, K., 1989. Information efficiency in the gold futures market: a semi-strong form test. Review of Futures Market 7, 78-88.

Ortiz-Cruz, A., Rodriguez, E., Ibarra-Valdez, C., Alvarez-Ramirez, J., 2012. Efficiency of crude oil markets: Evidences from informational entropy analysis. Energy Policy 41, 365-373.

Sephton, P.S., Cochrane, D.K., 1990. A note of the efficiency of the London metal exchange. Economic Letters 33, 341-345.

Sephton, P.S., Cochrane, D.K., 1991. The efficiency of the London metal exchange: another look at the evidence. Applied Economics 23, 669-674.

Shambora, W.E., Rossiter, R., 2007. Are there exploitable inefficiencies in the futures market for oil? Energy Economics 29, 18-27.

Solt, M.E., Swanson, P.J., 1981. On the efficiency of the markets for gold and silver. Journal of Business 54, 453-478

Switzer, L.N., El-Khoury, M., 2007. Extreme volatility, speculative efficiency, and hedging effectiveness on the oil futures markets. Journal of Futures Markets 27, 61-84.

Tabak, B.M., Cajueiro, D.O., 2007. Are the crude oil markets becoming weakly efficient over time? A test for time-varying long-range dependence in prices and volatility. Energy Economics 29, 28-36.

Taylor, M.P., 1995. The economics of exchange rates. Journal of Economics Literature 33, 13-47.

Tschoegl, A.E., 1980. Efficiency in the gold market - a note. Journal of Banking and Finance 4, 371-379.

Van Dijk, D., Franses, P.H., Paap, R., 2002. A nonlinear long memory model with an application to US unemployment. Journal of Econometrics 110, 135-165.

Wang, H.H., Ke, K.B., 2005. Efficiency tests of agricultural commodity futures markets in China. Australian Journal of Agricultural and Resources Economics 49, 125-141.

Wang, Y., Wei, Y., Wu, C., 2011. Analysis of the efficiency and multifractality of gold markets based on multifractal detrended fluctuation analysis. Physica A: Statistical Mechanics and its Applications 390, 817-827.

Watkins, C., McAleer, M., 2006. Pricing of non-ferrous metals futures on the London metal exchange. Applied Financial Economics 16, 853-880. 